\title{
BIRTH WEIGHT AND THE SURVIVAL OF BABIES OF DIABETIC WOMEN*
}

\author{
BY \\ JAMES W. FARQUHAR \\ From the Department of Child Life and Health, University of Edinburgh, and Simpson Memorial \\ Maternity Pavilion, Royal Infirmary, Edinburgh
}

(RECEIVED FOR PUBLICATION NOVEMBER 27, 1961)

The high perinatal mortality among the babies of diabetic women is often thought to be directly proportionate to their birth weight, but in an earlier analysis of the Edinburgh series the smaller babies at any gestational age were found to be at greater risk. It was also apparent that some pre-diabetic and diabetic women can bear whole families of large babies who progress normally, while others have a dismal record of foetal loss which may be independent of the duration of maternal diabetes or of the quality of its control (Farquhar, 1959). The disparity between these observations and conventional opinion has prompted this re-examination of the subject in a larger series.

\section{Material}

A total of 204 viable pregnancies has now been studied, and in each of them a firm diagnosis of maternal diabetes mellitus has been made. All the women concerned have received their diabetic and obstetric care at the same hospital from one physician and, for the most part, from one obstetrician along lines previously described (Rolland, 1954; Farquhar, 1959), and most of them received insulin. No attempt has been made to group them by severity according to White's (1952) classification. All the babies have been examined by one paediatrician, and information has been obtained about the maturity and birth weight of their siblings not only from the mothers, but wherever possible from hospital records. The study, therefore, comprises 208 personally observed infants of whom 43 were only children, and a further 181 siblings who were delivered out with the series.

\section{Results}

Family Patterns of Birth Weight. The babies are shown linked together in families (Fig. 1a and b),

\footnotetext{
* The substance of a paper read at the Round Table Conference on Diabetic Pregnancy, held as part of the IVth Congress of the International Diabetes Federation, Geneva, 1961.
}

and the birth weight of each infant is plotted against that year of the mother's diabetic life in which it was born. Family birth weights may be consistently high in each pregnancy over many years (Example: 1/191,* $17 / 9$ and 18/8), or they may increase steadily (Example : 3/134, 6/151 and 10/94), or decrease (Example: 4/171, 7/112 and 18/13), or vary irregularly (Example: 2/186, 8/115 and 9/209).

Family Patterns of Mortality. The babies are again linked together in families (Fig. 2), and each infant is plotted against that year of the mother's diabetic life in which it was born. The pre-diabetic years feature a total of 185 infants with a perinatal mortality of $13.5 \%$, and the diabetic years have 203 of them with a perinatal mortality of $25 \%$. (In the 43 primiparous and frankly diabetic pregnancies not shown on the graph it is $23 \%$.) In the 35 pregnancies in which diabetes was first diagnosed the perinatal mortality is $37 \%$. Furthermore, of the 108 families represented, 57 of them (comprising a total of 185 babies) are unmarred by a single death, whereas in the other 51 families (and 203 babies) the perinatal mortality is $38 \%$. Thus more than half of the women in the series gave birth to at least two children without loss, and rather less than half of them shared the 77 foetal deaths. Of those 57 families who were without foetal loss, 28 entire families were delivered during the mother's diabetic years and, as in family 44 , many years after the diagnosis of diabetes mellitus had been made. This freedom from foetal loss is not always clearly dependent upon the quality of diabetic control.

Heavy Babies and Mortality in Families. The birth weights and the death or survival of individual babies in families may be compared by studying Figs. 1 and 2. (A small number of babies are

* Where 1 is the number of the small inset graph and 191 is the number of the family. 

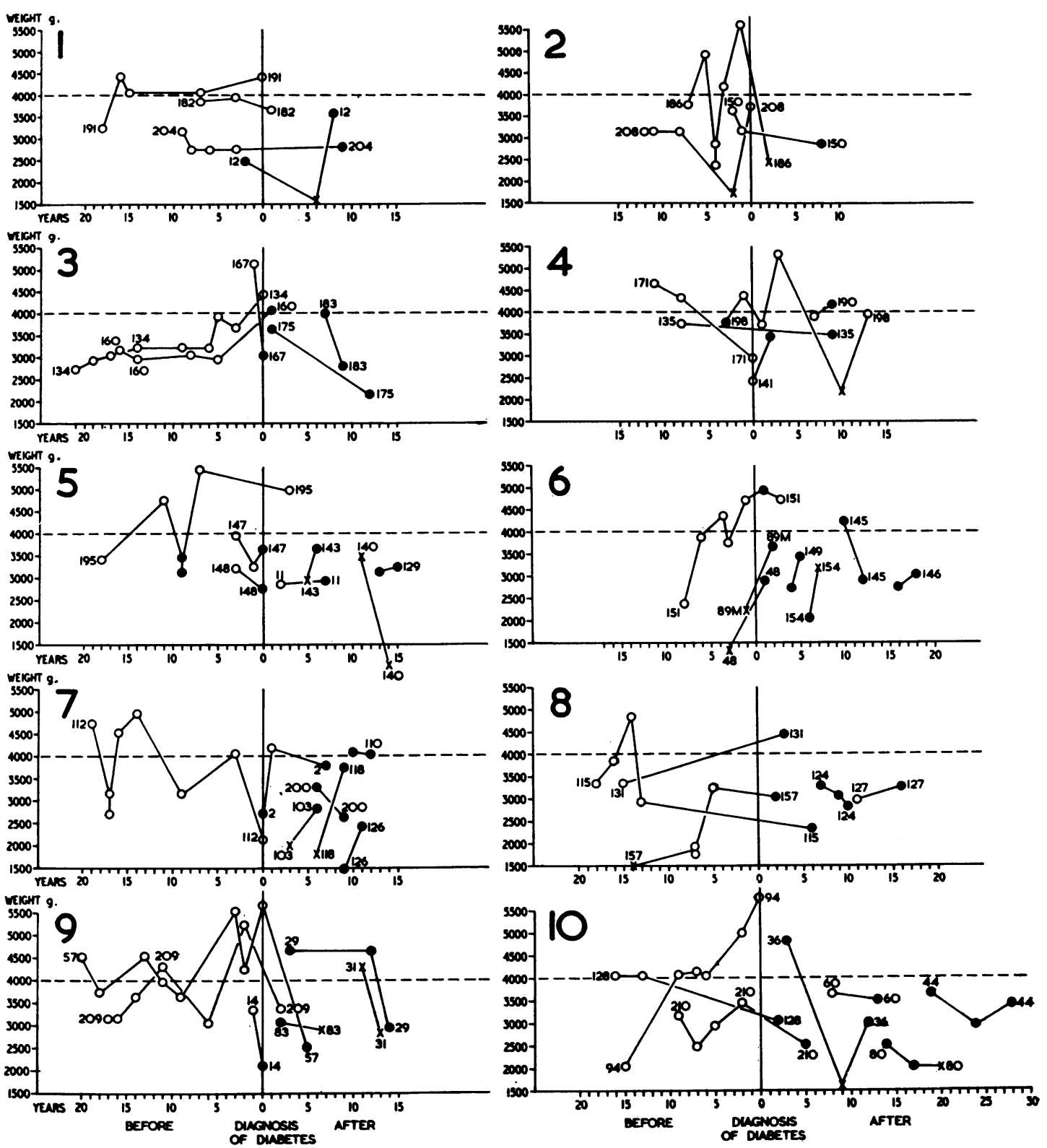

FIG. 1a.-Family birth weights and duration of maternal diabetes. The birth weights of babies, arranged in families, shown against that year of the mother's pre-diabetic or diabetic life in which each was born. Gestational age: $O=$ full term; $=35-38$ weeks; $x=<35$ weeks.

omitted from Fig. 1 because of uncertainty about their birth weights.) Such comparison shows that high or persistently increasing birth weights are compatible with a good survival rate (Example: $1 / 191,6 / 151,10 / 94,15 / 15$ and 17/9).
Idiopathic Respiratory Distress Syndrome and Perinatal Mortality in Relation to Gestational Age and Birth Weight. The birth weight and perinatal state of each baby born to a diabetic mother in the hospital between 1948 and 1961 is shown against 

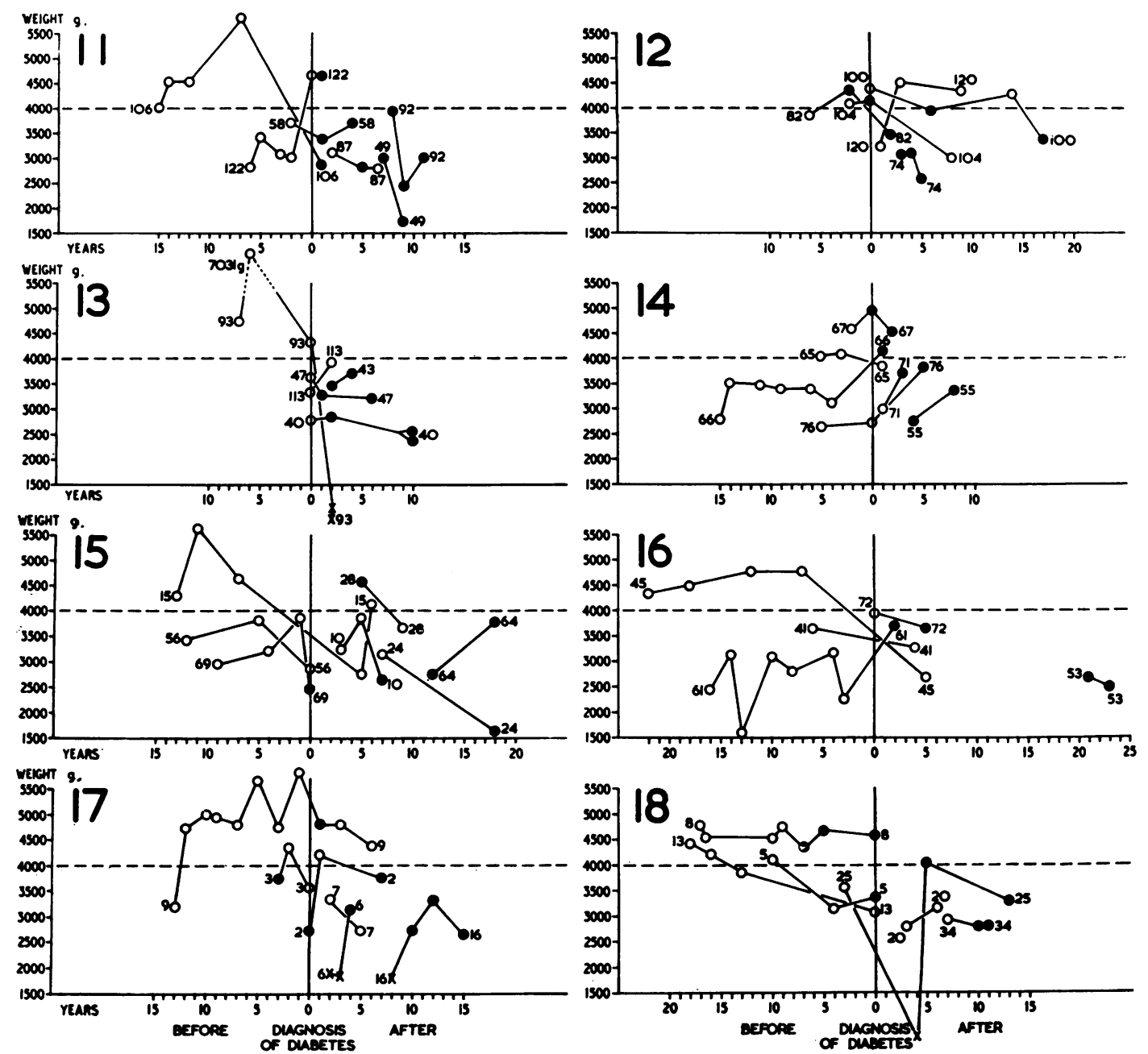

FIG. 1b.-Family birth weights and duration of maternal diabetes. The birth weights of babies, arranged in families, shown against that year of the mother's pre-diabetic or diabetic life in which each was born. Gestational age: $O=$ full term; $=35-38$ weeks; $x=<35$ weeks.

gestational age (Fig. 3); 87 of them exceeded 3,000 g. and 118 weighed $3,000 \mathrm{~g}$. or less. The mean curve of birth weight at various gestational ages in non-diabetic pregnancy at the same hospital (Ellis, 1951) is shown. The incidence of the idiopathic respiratory distress syndrome (with survival), of

TABLE

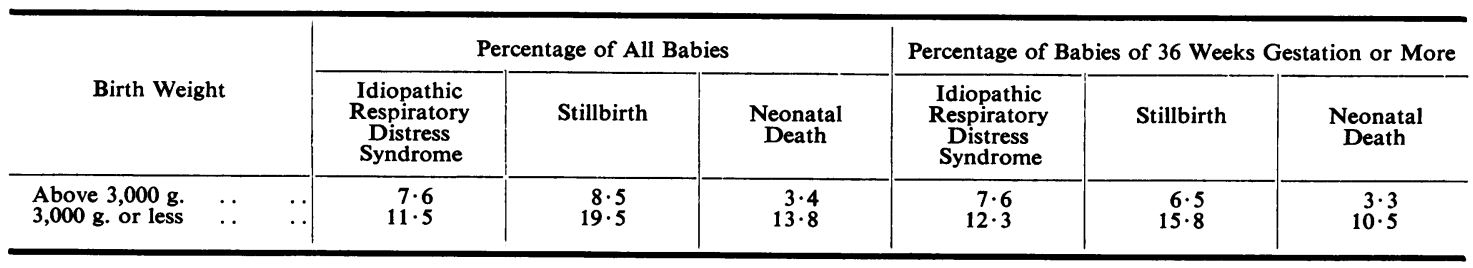




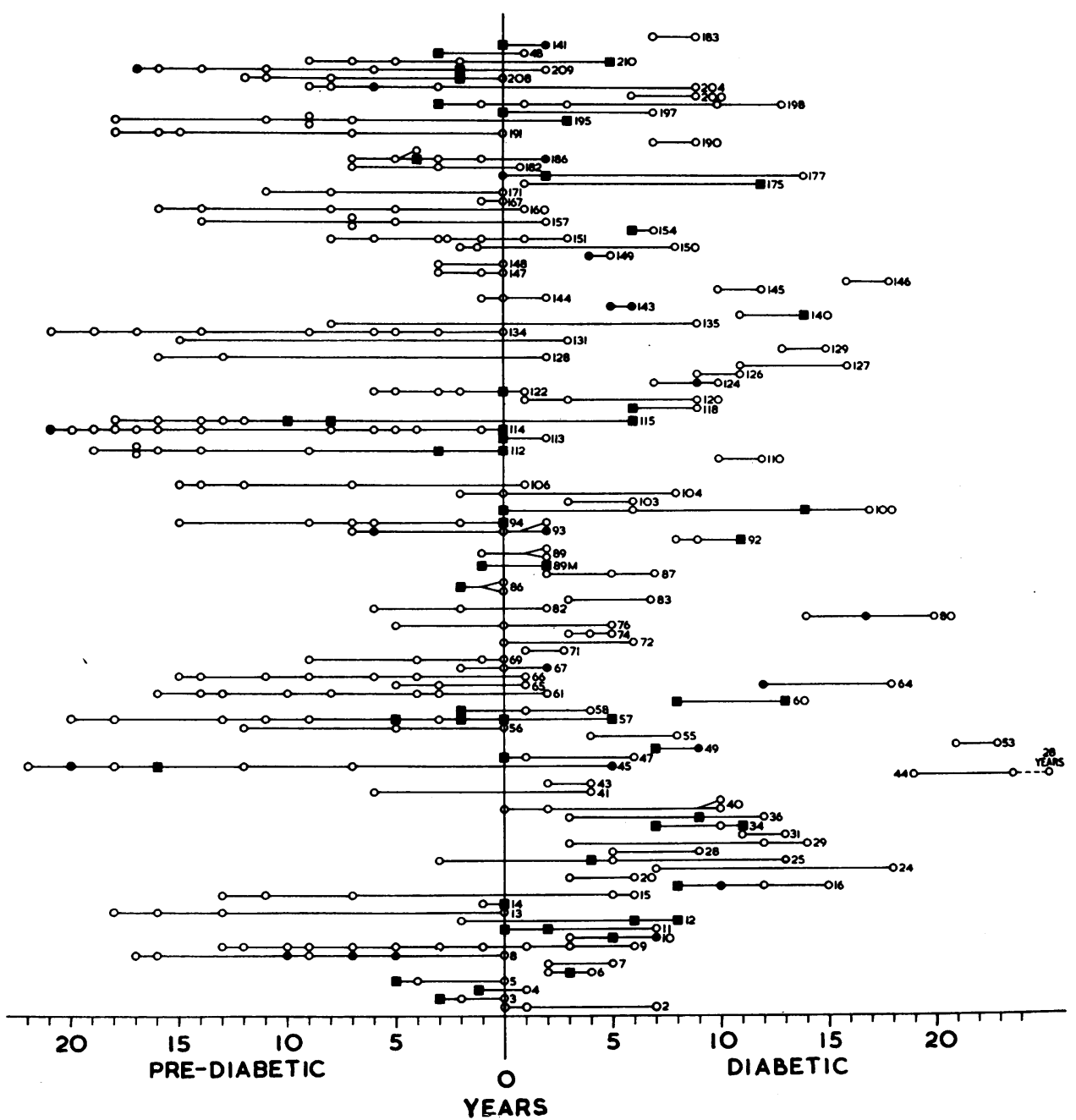

Fig. 2.-Showing viable foetal mortality in diabetic women. Babies, arranged in families, shown against that year of the mother's prediabetic or diabetic life in which each was born and showing stillbirth, neonatal death and survival. $\square=$ stillbirth; $=$ neonatal death; $\mathrm{O}=$ survival.

stillbirth, and of neonatal death is appreciably smaller among those infants of above $3,000 \mathrm{~g}$. birth weight than it is for those of this weight or less, and this holds true even if only those babies of 36 weeks gestation or more are considered (Table).

\section{Discussion}

The infant of the diabetic woman is often described as a large, bloated and frankly oedematous baby suffering from severe, often lethal, respiratory problems during the first few days of life. Such a belief stems from the facts that as a group such babies are fat and that again as a group they commonly have respiratory distress. Thus distur- bances of function, dyspnoea and even death come to be regarded as inevitable accompaniments of increasing birth weight, and this conception may lead in turn to the belief that both foetal gigantism and the high perinatal mortality have a common cause. Such assumptions are often misleading, and some have already been challenged. It is now known, for example, that these babies can tolerate very low blood sugar levels without disturbance (Farquhar, 1956a), that the postnatal weight loss is not abnormal, and also that their excessive weight is not due to oedema (Farquhar and Sklaroff, 1958).

Where foetal size is sufficient to obstruct vaginal delivery, then it may of course cause foetal death 


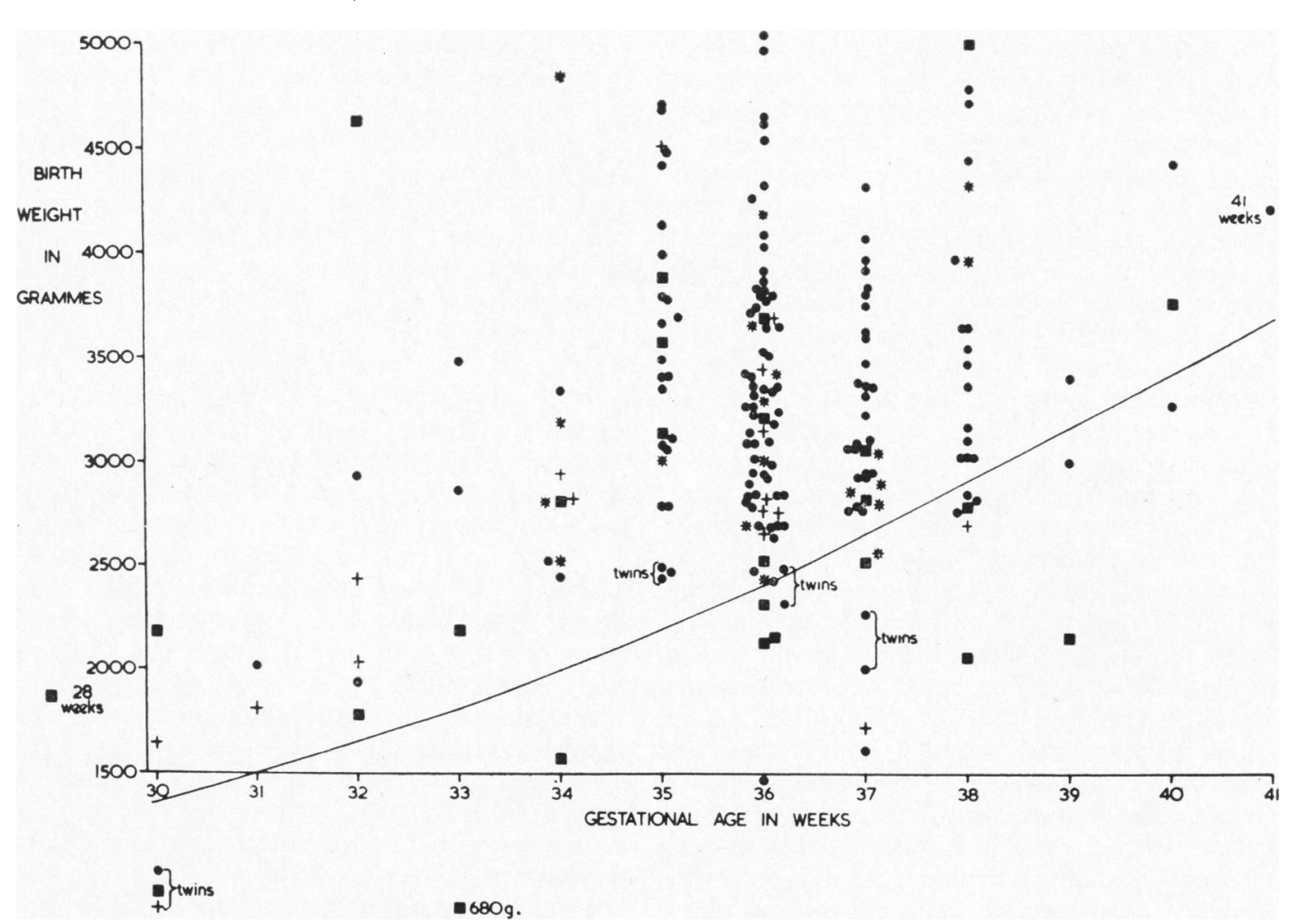

FIG. 3.-The peri-natal state of babies born to diabetic women plotted against birth weight and gestational age. $+=$ neonatal deaths; $*=$ respiratory distress; $\square=$ stillbirths; $O=$ survived.

(Bennewitz, 1828), and this long-recognized problem has done much to create the image of an incarcerated giant dying of anoxia. The existence of a positive correlation between excessive weight and increased mortality seems to gain some support from the observation of Pedersen (1952) and of Oakley (1961) that rigid control of the maternal diabetes in pregnancy reduces not only the mortality but also the foetal birth weight. In the very large Boston series of autopsies on such babies excessive birth weight was exceptional (Driscoll, Benirschke and Curtis, 1960), and although this could mean that the diabetic control there, and therefore foetal size, compares favourably with that in Copenhagen, it could also mean that, with good conditions of delivery, larger babies survive.

The demonstration by Osler (1960) that the excessive weight of infants of diabetic mothers is due mostly to increased fat is consistent with
Pedersen's thesis (1952) that maternal hyperglycaemia promotes foetal insulin secretion and consequent obesity. Thus, other things being equal, successive pre-diabetic pregnancies in which maternal glucose tolerance is progressively impaired should produce babies of increasing birth weight until the point is reached where good insulin control is established, and thereafter further infants should weigh less. Some families, but not all, in the present series have behaved in this way, and there must be other factors such as inheritance (Pyke, 1960) which can explain such birth weight trends as family $17 / 9$ or 18/13 (Fig. 1b). The possible promotion of foetal overgrowth by pituitary growth hormone or by adrenocortical steroids has been convincingly dismissed by Osler and Pedersen (1960), while experimental evidence which could support Pedersen's 'hyperglycaemia hypothesis' has been provided by Baird and Farquhar (1962) who have shown that 
the pancreatic islet beta cells of such infants are much more responsive to a glucose load than are those of normal babies. Whatever the means by which this increased insulin secretion is achieved, there is evidence that it may serve in the young animal to promote not only obesity but increased growth (Farquhar, 1956b). Such a process of increasing body weight, and possibly body length, is so physiological, however, that it is an unlikely cause of an overall viable foetal perinatal mortality of about $20 \%$ in most series and never less than $10 \%$ even in the best. Osler (1960) has suggested that obesity, by increasing the resistance to chest expansion and by impeding the circulation, may place an extra strain upon the heart and contribute toward the common signs of cardiopulmonary insufficiency during the first few hours of life. He also suggests that cardiac embarrassment and circulatory overloading may be increased by the release of water from glycogen depots soon after birth. But if these were so, then a higher incidence of idiopathic respiratory distress syndrome, or even of death, could be expected among heavy babies born during the pre-diabetic or diabetic years of the mother's life. This is by no means so in the Edinburgh series, in which some mothers have had big families of heavy babies none of whom has had an abnormal neonatal course, and the larger babies in the series as a whole have a better prognosis than the smaller ones. Indeed, there may be a broad optimum weight range at any gestational age with increased risk of foetal disturbance or death existing at the upper and lower extremes of it. Thus the cause, or causes, of disturbed function and of foetal death appear to be more than the increased secretion of insulin and the possible consequent promotion of obesity and overgrowth.

As the majority of viable foetal deaths in this and in many other series are intrauterine, the factor or factors which prejudice survival must operate before the development of the neonatal hypoglycaemia, hypocalcaemia, hyperpotassaemia, hypopotassaemia, hyperbilirubinaemia, pulmonary hyaline membrane, hypotension, patency of the ductus arteriosus and cardiac failure to which the neonatal disturbances have been ascribed, although one or more of these may play an important secondary role. Severe diabetic ketosis in pregnancy can kill both mother and baby, and lesser degrees of poor control are also associated with a high viable foetal mortality as, for example, in this series where it is highest in those pregnancies during which the diagnosis of diabetes mellitus was made. It is also indisputable that the almost perfect diabetic control achieved in the Rigshospitalet, Copenhagen, can reduce the viable foetal mortality to a figure approaching $10 \%$, but even this is much higher than in non-diabetic pregnancy. Furthermore, this study strongly suggests the existence of a factor which, because of the variable degree of malignity with which it presents from woman to woman, may cause foetal death in the presence of strict diabetic control or permit foetal survival in the presence of continuous maternal hyperglycaemia. In this connexion the adequacy of some placental functions in diabetic pregnancy has been questioned, White (1952) having claimed that hormonal imbalance is an important and remediable cause of foetal death, while MacKay (1957) and Prystowsky (1957) have suggested that oxygen transfer to the foetus may be impaired. More recently Brudenell, Miles and Coleman (1961), using the radioactive sodium technique, have found that there is no reduction in myometrial blood flow in late diabetic pregnancy, but the method measures only myometrial flow and it does not measure placental flow, maternal or foetal, or placental function. The placenta, which ages rapidly even in normal pregnancy, is a very vascular structure containing not only blood spaces but very many small vessels which in the villi are extremely delicate and exposed to the maternal diabetic milieu. The changes which occur in the microcirculation throughout the body of the diabetic subject are well known (Colwell, 1960). The obvious changes which can be recognized in the diabetic retina are probably long preceded by increasing width of venules in relation to arterioles and by the sludging of red cells in capillaries. Some opposition to the acceptance of these reported changes has come from those whose examining instrument is the ophthalmoscope rather than the microscope, and as some of the changes are dynamic they are difficult to present for objective analysis and can be criticized as subjective misinterpretation. The technique of microscopy of the bulbar conjunctiva in the living subject is extremely difficult, but Ditzel and his colleagues, in a series of papers describing the changes in diabetes, have shown how rapidly these may progress in pregnancy, and have claimed that they are also detectable in some children of diabetic mothers (Ditzel, White and Duckers, 1954; Ditzel, 1956; Ditzel and Moinat, 1957; Bech, Hansen, Lorentzen and Lundbaek, 1960). Such changes are illustrated in Fig. 4, which consists of photographs taken through a microscopic system with moderate magnification of the bulbar conjunctiva of a healthy adult and of a young pregnant diabetic woman with nephropathy and retinopathy. The nature of these small vessel changes has been studied extensively in 


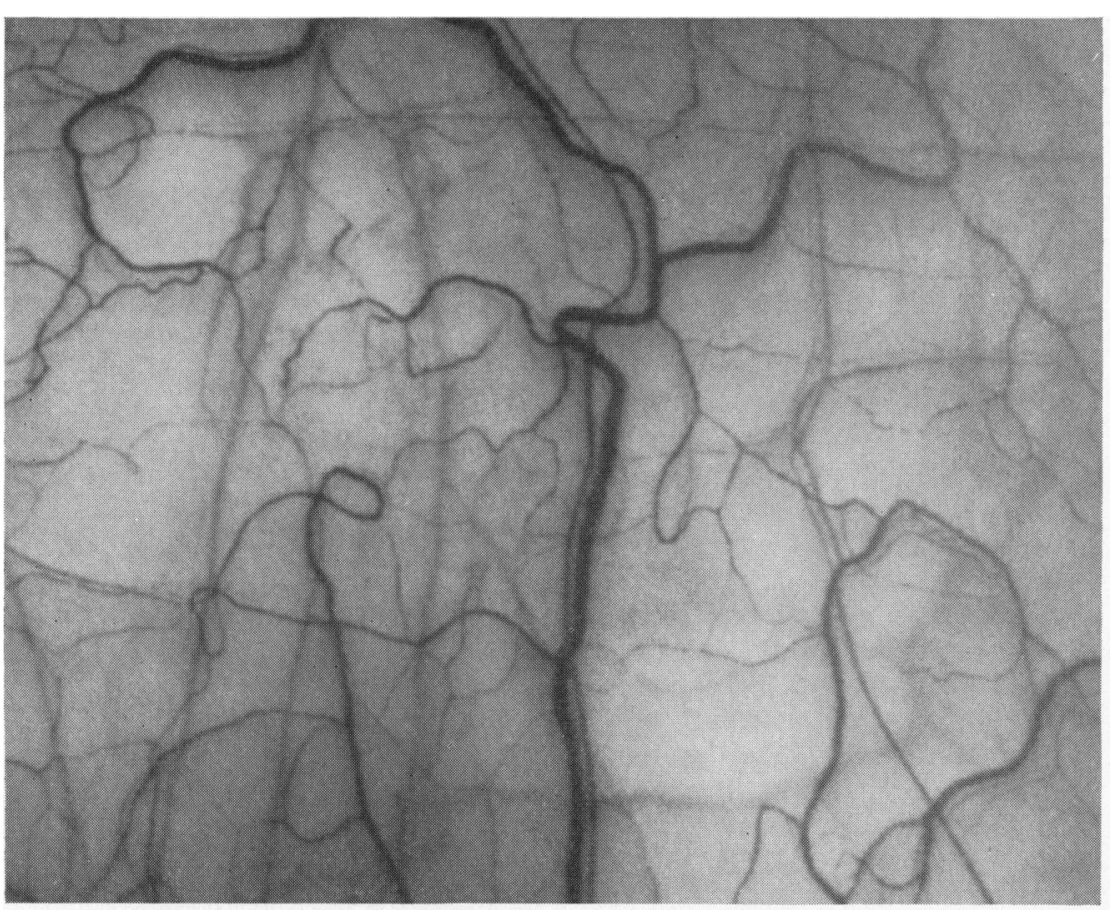

(a)

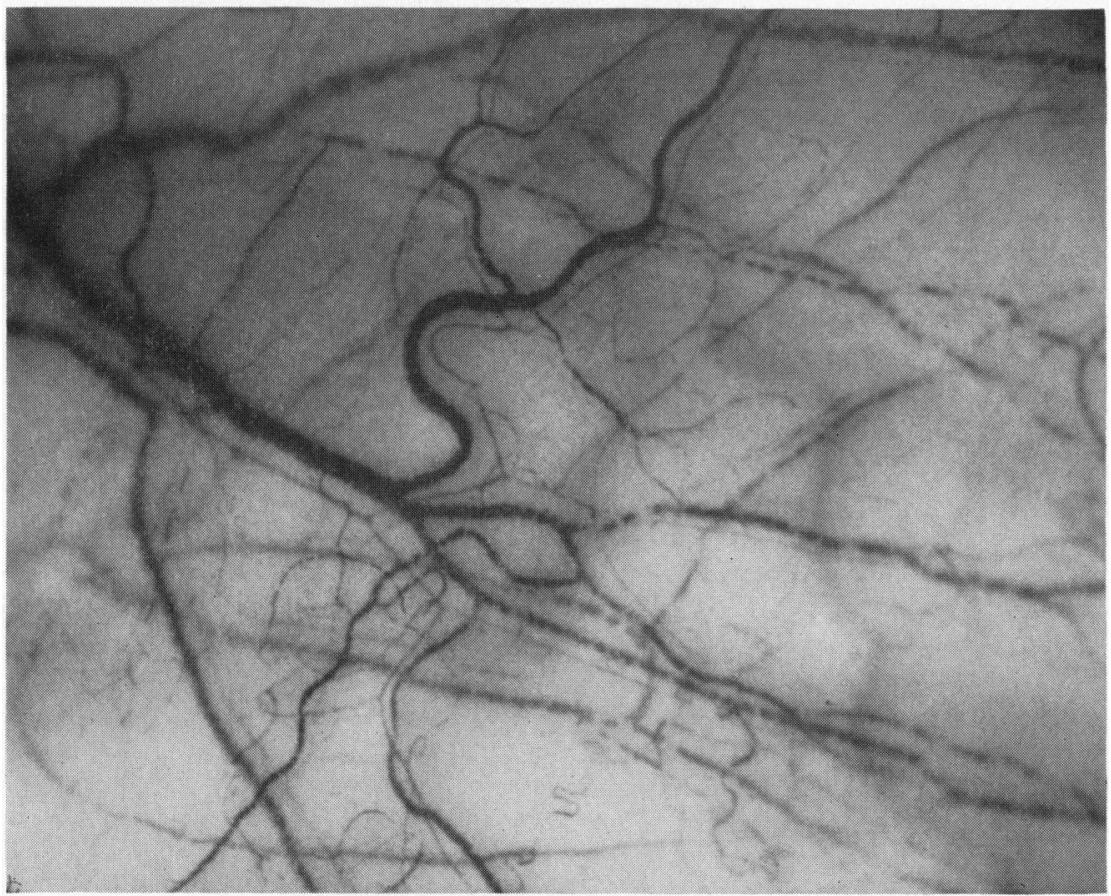

(b)

FiG. 4.- The small vessels of the bulbar conjunctiva in $(a)$ a healthy adult and $(b)$ a pregnant diabetic with nephropathy and retinopathy, showing in the decreased ratio of artery to accompanying vein in diabetes and the sludging of red cells. 
St. Louis where those found in the limbs have been distinguished clearly from those found in nondiabetics and in arteriosclerosis (Goldenberg, Alex, Joshi and Blumenthal, 1959). They are just as characteristic in the coronary circulation (Blumenthal, Alex and Goldenberg, 1960), where their principal effects seem to be interference with the development of collateral circulation, and they are also apparent in the skin capillaries (Aagenaes and Moe, 1961). Such changes can endanger the survival of a limb or of a heart, the function of a retina or of a kidney, and it seems possible that less pronounced changes may so interfere with the urgent needs of supply to and elimination from a rapidly developing foetus that it may cause stunting, undernutrition and death even in the presence of maternal hyperglycaemia and an increased foetal capacity for secreting insulin. Those babies which are born to diabetic women with nephropathy are certainly known to be smaller than those born to women whose diabetes is uncomplicated in this way, and they have an appreciably higher mortality (Oppé, Hsia and Gellis, 1957). It is of considerable interest, therefore, that, although previous careful studies, other than those of MacKay (1952) who described the existence of stromal oedema in the rapidly fixed tissue, had revealed no specific abnormality in the diabetic placenta, Burstein, Soule and Blumenthal (1957) described a specific obliterative endarteritis in the maternal vessels. Placental tissue is difficult to obtain and handle with the necessary speed and gentleness which are essential for electron microscopy, and this probably explains why such a study of the diabetic placenta has not been undertaken, for it is likely that abnormalities of the small vessels could be found.

Diabetic changes in the microcirculation may be related to abnormalities of the protein fractions in the serum (Ejarque, Marble and Tuller, 1959; Ditzel and Moinat, 1959), which can be prevented or removed by good control aided by a diet rich in unsaturated fatty acids. There is still no evidence, however, that foetal mortality can be correlated with the protein changes of either the diabetic mother or her baby (Lloyd, 1961).

\section{Summary}

The foetus of a diabetic woman, cribbed and forcibly fed with glucose in utero, may become excessively large partly because of increased insulin activity and partly perhaps for genetic and other reasons. Where obstetric care is good, however, the larger baby has a better immediate prognosis than the smaller one. There may be an as yet unrecognized factor independent of diabetic control which is harmful to the foetus and which is more active in some women than in others. This may exert its effect upon the small blood vessels of the placenta.

I wish to thank Professor Richard W. B. Ellis for his continued interest and support in this study. The conjunctival photographs were made possible by the personal help of Dr. Harold E. Edgerton of the Massachusetts Institute of Technology, Cambridge, Mass., and I gladly acknowledge his interest and kindness. Conjunctival examination and photography were made possible by the Type LS-15 Flash Illuminator (Edgerton, Germeshausen \& Grier, Inc., Boston, Mass). I again record my thanks to Miss Elizabeth Meiklejohn for a wealth of secretarial help.

\section{REFERENCES}

Aagenaes, O. and Moe, H. (1961). Light- and electron-microscopic study of skin capillaries of diabetics. Diabetes, 10, 253 .

Baird, J. D. and Farquhar, J. W. (1962). The insulin-secreting capacity of the pancreas in the newborn infants of normal and diabetic women. Lancet, 1,71 .

Bech, K., Hansen, E., Lorentzen, S. E. and Lundbaek, K. (1960). The V/A ratio of the smaller vessels of the bulbar conjunctiva in diabetes mellitus. Diabetes, $9,441$.

Bennewitz, H. G. (1828). Symptomatic diabetes mellitus. (Report of a case described by Bennewitz in Osann's 12 ter Jahresbericht des Poliklinischen Institutes zu Berlin, p. 23.) Edinb. med. surg.J., 30, 217.

Blumenthal, H. T. Alex, M. and Goldenberg, S. (1960). A study of lesions of the intramural coronary artery branches in diabetes mellitus. Arch. Path. (Chicago), 70, 13.

Brudenell, J. M., Miles, J. M. and Coleman, A. (1961). The clearance of radioactive sodium from the myometrium of the pregnant diabetic. J. Obstet. Gynaec. Brit. Cwlth., 68, 238.

Burstein, R., Soule, S. D. and Blumenthal, H. T. (1957). Histogenesis of pathological processes in placentas of metabolic disease in pregnancy. II-The diabetic state. Amer. J. Obstet. Gynec. 74,96

Colwell, A. R. (1960). Histology of small blood vessel disease in diabetes. Diabetes, 9, 503 .

Ditzel, J. (1956). Angioscopic changes in the smaller blood vessels in diabetes mellitus and their relationship to aging. Circulation, 14, 386.

- and Moinat, P. (1957). The responses of the smaller blood vessels and the serum proteins in pregnant diabetic subjects. Diabetes, 6, 307.

- (1959). Changes in serum proteins, lipoproteins, and protein-bound carbohydrates in relation to pathologic alterations in the microcirculation of diabetic subjects. J. Lab. clin. Med., $54,843$.

, White, P. and Duckers, J. (1954). Changes in the pattern of the smaller blood vessels in the bulbar conjunctiva in children of diabetic mothers. Diabetes, $3,99$.

Driscoll, S. G., Benirschke, K. and Curtis, G. W. (1960). Neonatal deaths among infants of diabetic mothers. Amer. J. Dis. Child., 100,818 .

Ejarque, P., Marble, A. and Tuller, E. F. (1959). Proteins, lipoproteins and protein-bound carbohydrates in the serums of diabetic patients. Amer. J. Med., 27, 221.

Ellis, R. W. B. (1951). Assessment of prematurity by birth weight, crown-rump length, and head circumference. Arch. Dis. Childh., 26, 411.

Farquhar, J. W. (1956a). The significance of hypoglycaemia in the newborn infant of the diabetic woman. ibid., 31, 203.

(1956b). The possible influence of hyperadrenocorticism on the foetus of the diabetic woman. ibid., 31, 483 .

(1959). The child of the diabetic woman. ibid., 34, 76

and Sklaroff, S. A. (1958). The post-natal weight loss of babies born to diabetic and non-diabetic women. ibid., 33, 323

Goldenberg, S., Alex, M., Joshi, R. A. and Blumenthal, H. T. (1959). Nonatheromatous peripheral vascular disease of the lower extremity in diabetes mellitus. Diabetes, 8, 261.

Lloyd, A. V. (1961). Observations on the composition of the blood in the neonatal period. Unpublished thesis.

MacKay, D. G. (1952). Reported by P. White in The Treatment of Diabetes Mellitus, 9th ed., p. 696, ed. E. P. Joslin, H. F. Riaot, P. White and A. Marble. Lea and Febiger, Philadelphia.

MacKay, R. B. (1957). Observations on the oxygenation of the foetus in normal and abnormal pregnancy. J. Obstet. Gynaec. Brit. Emp., 64, 185. 
Oakley, W. G. (1961). Round table conference on pregnancy in diabetes. IVth Congress of the International Diabetes Federation.

Oppé, T. E., Hsia, D. Y.-Y. and Gellis, S. S. (1957). Pregnancy in the diabetic mother with nephritis. Lancet, 1, 353.

Osler, M. (1960). (a) Body water of newborn infants of diabetic mothers; (b) Body fat of newborn infants of diabetic mothers; (c) Renal function of newborn infants of diabetic mothers; (d) Neonatal changes in body composition of infants born to diabetic mothers. Acta endocr. Kbh., 34, 261.

and Pedersen infants of diabetic mothers. Pediatrics, 26, 985.
Pedersen, J. (1952). Diabetes and Pregnancy. Blood Sugar of Newborn Infants. Danish Science Press, Copenhagen.

Prystowsky, H. (1957). Fetal blood studies. VII. The oxygen pressure gradient between the maternal and fetal bloods of the human in normal and abnormal pregnancy. Bull. Johns Hopk. Hosp. $101,48$.

Pyke, D. A. (1960). The Genetics of Heavy Babies. British Diabetic Association Meeting, Glasgow.

Rolland, C. (1954). Diabetes in pregnancy. Edinb. med. J., 61, 257. White, P. (1952). In The Treatment of Diabetes Mellitus, 9th ed., p. 676, ed. E. P. Joslin, H. F. Root, P. White and A. Marble. Lea and Febiger, Philadelphia. 